\title{
'The sad language of pain': S. Weir Mitchell, the American Civil War, and interpreting physical suffering
}

Book or Report Section

Accepted Version

Bending, L. (2018) 'The sad language of pain': S. Weir Mitchell, the American Civil War, and interpreting physical suffering. In: Gonzalez-Polledo, E. J. and Tarr, J. (eds.) Painscapes: framing pain communication. Palgrave Macmillan, London, UK, pp. 25-40. ISBN 9781349952717 Available at http://centaur.reading.ac.uk/72775/

It is advisable to refer to the publisher's version if you intend to cite from the work. See Guidance on citing.

Publisher: Palgrave Macmillan

All outputs in CentAUR are protected by Intellectual Property Rights law, including copyright law. Copyright and IPR is retained by the creators or other copyright holders. Terms and conditions for use of this material are defined in 
the End User Agreement.

www.reading.ac.uk/centaur

\section{CentAUR}

Central Archive at the University of Reading

Reading's research outputs online 
'The sad language of pain': S. Weir Mitchell, the American Civil War, and interpreting physical suffering

"If a man positively affirms that he suffers great pain in some portion of his body, it seems to the popular mind absurd for a surgeon to affirm that he does not."1

This chapter's aim is to use the tensions inherent in the American Civil War Army Assistant Surgeon, J. J. Woodward's claim as a starting position to consider some of the difficulties in expressing and understanding pain. For Woodward, steeped in the terrible carnage of the Civil War, what constitutes physical pain - what the surgeon envisages as arising from a bodily injury - is at odds with - is perhaps less to be taken into account by the general public - than the simple affirmation of that pain by the sufferer. It is only when a patient affirms pain, perhaps performs that pain, that it becomes visible to another, And yet there is, as Woodward is clearly suggesting, a possibility, that flies in the face of popular understanding, that a claim to pain may not be genuine; may not grow out of a bodily reality that could be recognized by a medical practitioner. The gap between sufferer and perceiver complicates things; means that the experience of pain cannot be simply passed from one person to another, but - if it is not to be seen as 'foreign'- must undergo a process of translation, as words are found, or symptoms are seen and interpreted. The foreignness of pain is not, however, the only difficulty for the surgeon who meets it on the battle field. Whilst Woodwards' fellow Army doctor, renowned neurologist, man of letters, and contemporary, Silas Weir Mitchell, sees pain as a language that is spoken, a language that can articulate suffering, there is another pervasive idea that underlies Mitchell's thought, and it is this that is the focus of this chapter. Pain is not a simple given, but is a kind of performance. Mitchell writes of the 'production

1 Joseph Janvier Woodward, Outline of the Chief Camp Diseases of the United States Armies as Observed During the Present War. A Practical Contribution to Military Medicine (Philadelphia: Lippincott) 1868: 326. 
of... pain',2 invoking in that word 'production' both the physical processes of the body in response to trauma, and the performance of that pain, that must be staged by sufferers if they are to convince an onlooker of its reality.

This chapter seeks to think about what it means to listen to what Mitchell, called 'the sad language of pain', but also what it means to judge the reality of that language against the patient's performance of pain; how the body reacts rather than what the patient himself says, as the two processes of translation and production run alongside each other, in a negotiation that has implications for the wider understanding of pain and its articulation.

It is by no means new to think about the necessity of listening to those in pain, and, indeed, much of the work done in this area stems from Elaine Scarry's ground-breaking The Body in Pain (1985), which articulates both the difficulties of voicing pain and the absolute necessity for hearing, and paying attention to, such voicings of suffering. I am interested here, though, in exploring Weir Mitchell's written responses - predominantly his medical writings, but also, in part, his fiction - to physical suffering, primarily arising from his experience as a Civil War surgeon, and the ways in which he thought about pain and language; of who spoke and who listened, and if, in the end, the evidence offered by the speech of a sufferer was sufficient to necessitate belief in its reality. Mitchell's reputation, as Kay Ferguson Ryals rightly contends, has undergone a profound change since the mid nineteenth century. He is now predominantly known not for being the foremost American neurologist of the late nineteenth century, repeatedly designated 'the father of American neurology', but as the man who originated the Rest Cure, 'a famous, or infamous, treatment that was widely prescribed to "nervous" American women in the late nineteenth century, and thus as the reallife physician who served as the model for the notorious doctor-husband in Charlotte Perkins-

2 S. Weir Mitchell, George R. Morehouse, and William W. Keen, Gunshot Wounds and Other Injuries of Nerves (Philadelphia: Lippincott) 1864: 104. 104. 
Gilman's "The Yellow Wallpaper", a text which represents the Rest Cure as a devastating form of social control aimed at keeping ambitious women in their "places".'3 Ryals is undoubtedly right about this shift in Mitchell's posthumous reputation, and it is a shift that is also recognized in Nancy Cervetti's fascinating exploration of what she sees as the movement in Weir Mitchell from Civil War surgeon, who 'gives voice and visibility to human pain, transcending its mastery of the body and reducing its effect',4 as the specialist in neurological disorders translates observed bodily experience into a kind of language, to the post-bellum society doctor who 'chooses not to listen'5 to, refuses fully to see, the 'hysterical' women who come under his care. I think the arc of Cervetti's argument is right, and yet my focus is on the texts written during or immediately after the Civil War: Gunshot Wounds, and Other Injuries of the Nerves (1864) in which Mitchell, along with his collaborators George Morehouse and William Keen, voice many of their hesitations over the passage of pain from sufferer to perceiver; 'On Malingering', written with the same two colleagues, which outlines the possibility of duplicity in what people say about their own pain;6 and Injuries of Nerves (1872), a revised and extended rewriting of Gunshot Wounds, solely under Mitchell's name, and published seven years after the end of the Civil War.7 If Cervetti sees a shift from belief to doubt in Mitchell's approach to his patient's painful suffering, then I, whilst concurrently recognizing this movement in his approach to patients, also see his career as riven by doubt, right from the start, at the visible signs of the body, the ways in which these are performed and perhaps manipulated, and how one could understand them. For Mitchell a process is involved in the transmission of pain from one person to another, and it is a process of which Mitchell undoubtedly

3 Kay Ferguson Ryals, 'Bedside Manners and the Social Body: S. Weir Mitchell and the Virtues of Medical Practice', Dissertation submitted in partial satisfaction of the requirements for the degree of Doctor of Philosophy in English, Universty of California, Irvine: 1.

4 Nancy Cervetti, 'S. Weir Mitchell Representing “a hell of pain”: From Civil War to Rest Cure', Arizona Quarterly: A Journal of American Literature, Culture, and Theory, 59: 3 (Autumn 2003) 69-96: 87.

5 Cervetti, 88. Cervetti cites the sad case of Winifred Howells, William Dean Howells' daughter, who died of disease, after being written off, by Mitchell, as suffering from 'hypochondriacal illusions and obstinacy' (88).

6 William W. Keen, S. Weir Mitchell, George R. Morehouse, 'On Malingering, Especially in Regard to Simulation of Diseases of the Nervous System', American Journal of Medical Science 48 (1864) 367-394. Gunshot Wounds and 'On Malingering' both have all three authors' names on the title page, but for reasons of brevity I will be referring to Mitchell as the author of these works throughout.

7 S. Weir Mitchell, Injuries of Nerves and their Consequences, (Philadelphia: Lippincott) 1872. 
recognizes the limitations. Whilst, as I will suggest later in this chapter, Mitchell was determined to professionalize medicine, using, as one of the means to this end, his insistence on giving the fullest account of what he observed, he nevertheless repeatedly fell back on the recognition that 'we cannot in any way become sure' 8 when looking at another's pain, of what it is, or even if it is real. Absolute knowledge of another's suffering is impossible, though perhaps in that notion of becoming, of becoming sure, is an idea of movement towards another, as the patient performs their pain in such a way that it becomes recognizable, and as the watcher responds to that production of pain. The doctor must be convinced by the performance of suffering if he is to believe in its existence.

As Joanna Bourke makes plain in writing about the huge-scale injuries of the Civil War, it brought with it a level of injury that was a huge challenge - and, indeed, an opportunity for the ambitious for military surgeons. It was, as Bourke argues, 'a conflict of utmost savagery'; 9 a conflict in which over 600,000 American soldiers died, and 30,000 limbs were amputated, a major part of that damage being done by 'the new conical bullet or minié [which] proved to be more damaging to muscle and bone than its predecessors.'10 Nancy Cervetti extends these claims by writing of the effects of the minié: 'Because the soft lead flattened and broke apart upon hitting the human body, the destruction of tissue, bone, cartilage, and vein was massive. While the entrance wound was the size of a thumb, the exit wound could be the size of a fist, and when hit in the arm or leg, the ball could shatter the bone from of distance of six to ten inches.'11 Such damage was unprecedented, and demanded new kinds of medical attention, not least because of the damage done to the nerves by the passage of the bullet.

8 'On Malingering', 384.

9 Joanna Bourke, 'The art of medicine: Silas Weir Mitchell's The Case of George Dedlow', Lancet, 373 (April 18, 2009), 1332-1333: 1332.

10 Bourke, 1332.

11 Cervetti, 75. 
Mitchell recognized the opportunity, and, as Richard D Walter suggests, when, in 1862, his friend and former collaborator, the Surgeon General, William A Hammond, started to create a hospital designed specifically for soldiers with neurological injuries, Mitchell was determined to be involved,12 as were his colleagues William Keen and George Morehouse, all three of whom closely collaborated in their medical practice and in the research papers that grew out of this. As Mitchell put it in his autobiographical writings, collected together by Anna Robeson Burr, 'There I began to be interested in cases of nervous disease and wounds of nerves, about which little was then known. '13 The team of men built up their collection of neurologically-wounded soldiers, many of whom were amputees, at the Turner's Lane Hospital in Philadelphia, which came, rather bluntly, to be known as the 'Stump Hospital'.14 He set up an arrangement whereby he accepted patients that doctors working in other hospitals did not want or know how to treat: he took those with serious neurological damage, and swapped them for more straightforward, commonly-encountered patients. As he writes:

The great bulk of our patients has consisted of men who have been shifted from one hospital to another, and whose cases have been the despair of their surgical attendants. As the wounded of each period of the war have been cured, discharged, invalided, or died, every large hospital had left among the wards two or three or more strange instances of wounds of nerves. Most of these presented phenomena which are rarely seen, and which were naturally foreign to the observation even of those surgeons whose experience was the most extensive and complete. 15

These 'strange instances', with their unrecognisable pain, are 'foreign' to those who encounter them: they speak a language that cannot be understood, and can only be shifted from one place to another.

12 See Richard D. Walter, S. Weir Mitchell, M.D. Neurologist: A Medical Biography, Charles C Thomas (Springfield: Illinois), 1970: $47 \mathrm{ff}$.

13 Anna Robeson Burr, Weir Michell: His Life and Letters (New York: Duffield) 1929: 104.

15 Gunshot Wounds, 10 
Indeed, they cannot even be properly seen:

Nowhere were these cases described at length in the text-books, and, except in a single untranslated French book, 16 their treatment was passed over in silence; while even in the volume in question but a limited class of nerve lesions was discussed. In the great monographs on military surgery, this defect is still so complete, that wounds of nerves are there related rather as curiosities and as matters for despair than with any view to their full clinical study and systematic treatment.17

If Elaine Scarry argues that pain is wrapped in silence because it cannot be articulated, then the silence here is different: it is the silence of the medical practitioners, baffled by the severity of the injuries they encountered, who chose not to confront the phenomenon of pain. Silence grows from the unwillingness to describe symptoms and find treatments, rather than from the failure of the doctor to recognize the words of the wounded soldier. Mitchell in his Civil War medical text books recognizes and seeks to redress this 'defect'.

It is the reason - and Mitchell's explanation - for this lack of knowledge about injured soldiers with neurological damage that interests me in this chapter, as it points not just towards the unusualness of such wounds, and their concurrent pain, but also both a refusal to listen to such suffering, a refusal to engage with its strangeness, and that strangeness itself which made it seem that the body of the neurologically-wounded soldier was speaking a language that could not be understood. If pain could only be either a 'curiosity' or a matter for despair, then the patients in pain could not be easily engaged with. The refusal to engage turns the pain into something else, something beyond medical reach, making it an object of fear.

16 G.-B. Duchenne, De l'Électrisation localisée et de son application à la physiologie, à la pathologie et à la thérapeutique, (Paris: J-B Bailliere) 1855.

17 Gunshot Wounds, 10. 
This doubt as to what pain is, and whether it can be recognized, crosses over into the article, 'On Malingering, especially in regard to Simulation of Diseases of the Nervous System', which fascinatingly grapples with the question of how to tell if disease is real or feigned. The article, stemming from close engagement with soldiers suffering from neurological disorders, has at its centre the difficulty of knowing for certain if someone else's bodily suffering is real. All kinds of disorder and disease were feigned by soldiers seeking discharge from the army, 18 from deafness, to diarrhoea, to paralysis, but, as the three authors recognized, there is something particular about pain and its invisibility, its reliance on verbal testimony, that made it a unique symptom. As Mitchell writes, while 'pain is not a feigned disease, [it is] the most easily feigned symptom, the most difficult and often most apparently cruel to gainsay or deny, and, at the same time, the most available stronghold to which the malingerer can resort.'19 Doubting pain is - as we saw Woodward assert - in itself a kind of cruelty, and, indeed, this cruelty could stretch to strikingly harsh treatment at the hands of medical practitioners who refused to believe in the reality of the supposed malingerer's pain. Mitchell cites the case of an English naval surgeon who 'compelled a suspected malingerer, even by flogging, to lift and swing an eighteen pound weight with his arms, despite the most earnest entreaties and asseverations of agonizing pain in his shoulder.'20 Only after his 'earnest entreaties' have been denied, was the surgeon called on to evacuate 'two pounds of purulent matter' from the shoulder. The evacuated pus spoke louder than the man's words, which were insufficient to bear effective testimony to his suffering. In Mitchell's eyes, the surgeon becomes 'the author of this cruelty', as his doubt, and the flogging that follows from it, is a more coherent and powerful narrative than the sailor's own words.

\footnotetext{
18 The system of bounties paid to those who enlisted led to a system where men would sign up for service in the army, hiding a disability or illness, and then, after being paid for joining the army, would disclose the disability in the knowledge they would be discharged. They were then free to move to another area to repeat the process, making money from joining and discharging. For Mitchell's description of this process, see 'On Malingering', 384.

19 'On Malingering', 376.

20 'On Malingering', 368.
} 
Mitchell's doubts over the nature and action of power and the validity of speech in the face of pain come to the fore in his contention that it is difficult to court-martial a malingerer, 'since in many a case in which it is morally certain that the man is a malingerer, it is yet impossible to swear to it.'21 Medical certainty falls at the hurdle of 'such evidence as will convince a court of non-professional men.'22 Bodily suffering, or the lack of it, is turned into 'evidence', and, in this process, becomes a form of argument rather than a somatic reality. If the soldier can put forward convincing evidence of his pain, then the layman will not doubt it. As Mitchell counters, the malingerer 'frequently tells a pitiful story',23 or will 'whimper and even sob in an unmanly manner, which in itself alone should produce suspicion.'24 Such unmanly sobbing - what looks to the layman like the proof of pain becomes in the eyes of the surgeon evidence of his duplicity. 'No men are so apt to exaggerate and overact their part, nor any so apt to endeavour to move belief by backing their assertions by repetition and affirmation, as those who feign simple pain. Such means are necessary to bolster doubtful assertion only.'25 Pain is a performance, and yet it is one that can be shamelessly overacted. And yet there is another possibility, as Mitchell recognizes that the surgeon, faced with an enactment of pain, can become too convinced by his own evidence, too impressed by his 'dexterity in detecting deception',26 and gets to the point where 'in every "back case" we shall see a malingerer'.27 No performance can be sufficient to persuade, as every soldier falls under suspicion. What matters to him here is what is seen, rather than what is heard: the doctor's power to observe is more significant than the patient's power to assert his suffering. What one expects, what one is paid to detect, stands in the way of clear vision, of the ability to listen to the 'most earnest entreaties and asseverations', and sees only deceit.

21 'On Malingering', 369.

22 'On Malingering', 369.

23 'On Malingering', 377.

24 'On Malingering', 377.

25 'On Malingering', 377.

26 'On Malingering', 369.

27 'On Malingering', 369. 
Mitchell's article shores itself up with technologies and practices that will disclose deceit, that will be able to discern the difference between real pain and faked pain, will see through the duplicitous claims and overacted miseries of the malingerer to the real bodily pain of the genuinely suffering the galvanism that will jerk the malingerer's muscles into action, the ether that will take away the body's ability to control its actions, the spies who will watch the doubted soldier while he thinks no one is looking, the detailed observation of the way in which the supposedly lame man uses a walking stick. It becomes a battle between doctor and soldier as to whose words are to be the more powerful, as the soldier sees pain as 'the most available stronghold' available to him, a fortress that cannot be breached, whilst the surgeon counters with the anaesthesia that will dupe the doubted man's body into betraying itself, and which is 'summoned as a reserve to decide the fortunes of a doubtful day.'28 It is no mistake that in Mitchell's novel, , a book published in 18??, but which grows out of his Civil War experience, the malingerer in the novel is caught out by the surgeon's shrewdness, as he attempts to act out the surgeon's deliberately deceptive description of what pain looks like. As he produces the twisted back head that he thinks is the response to pain, the surgeon announces, 'That will answer', and sends him back to the battlefield. The body's answer is more compelling, more truthful, than that produced by the man's spoken words. Diagnosis is a battle field. There can be no absolute certainty, but the strongest argument will be prevail. And yet, in the face of this, 'such cases' as that of the flogged English sailor with the agonizingly purulent arm 'have', as Mitchell puts it, 'made us wary'29 in this battle between doubt and certainty. As he goes on to suggest, 'It is unfortunately the fact, that one rogue throws a shadow of suspicion on a dozen honest men,'30 and it is for this reason that Mitchell deliberately chooses to 'name' 31 these wrongly doubted solders, or at least draw attention to their existence in 'On Malingering'. In writing this treatise on malingerers, caught between compassion and caution, Mitchell voices his own doubt, 
and speaks the real pain of soldiers out loud and in so doing acknowledges the reality of their suffering. The danger is, as he all too sharply recognizes, that 'in endeavouring to do justice to the government, we be led unwittingly, to do injustice to the man.'32

And yet Union surgeons have a duty to the government they serve: malingerers must be found out and sent back to the field of battle. In fighting mode, Mitchell makes plain that 'where no other evidence than the man's assertion of pain exist, he should be sent back to his regiment'33 to fight. Assertion of pain is insufficient and fakeable, and yet the caveat that Mitchell adds to this statement is at the heart of the matter: 'But it should be understood that "no other evidence" is to be accurately determined.'34 Such a decision must not be based on a whim, but on proper, extensively documented, medical grounds. Gunshot Wounds insists on the seeking of evidence, on just such accurate determination of symptoms:

Our materials for this study consist of about one hundred and twenty cases, all of which have been carefully reported in our note books during the past year. No labor [sic] has been spared in making these clinical histories as perfect and full as possible. Those only who have devoted themselves to similar studies will be able to appreciate the amount of time and care which have been thus expended. We indulge the hope that we shall leave on record a very faithful clinical study of nerve injuries, and that we shall have done something at least toward lessening the inevitable calamities of warfare. 35

'Full' description on the doctors' part will somehow make up for the inability to trust or to understand the 'foreignness' of the patients' language. Mitchell's framing comments here clearly

32 'On Malingering', 369.

33 'On Malingering', 376.

34 'On Malingering', 376.

35 Gunshot Wounds, 11. 
establish the qualities that he values and the difficulties faced. All of the texts written during the Civil War by the doctors at the Stump Hospital relied on shared information, as the three doctors who worked together, decided who would write up which of the clinical observations that they made for publication. There is an insistence on information being unmediated; it must come straight from notes taken at the time of medical examination. No artefacts will be introduced by the passage of time, nor by the processes of memory and forgetfulness. Mitchell's stress is on the absolute care of the note takers: conditions are 'carefully reported', they are 'as perfect and full as possible', they have had great 'time and care ... expended' on them, and they are 'a very faithful clinical study'. The stress is very clearly on a direct transcription of the medical case itself. Ernest Earnest recounts the meticulous attention to detail of the record keeping at the Stump Hospital, making plain that 'a single case may take up five to nine pages of foolscap.'36 Conventions for case notes were standardised to ensure the 'full' account that Mitchell required, and cases could be followed for up to two years in these notes.37 As Kay Ferguson Ryals compellingly argues in her dissertation, Bedside Manners and the Social Body: S. Weir Mitchell and the Virtues of Medical Practice, 'Mitchell's team' at the Stump Hospital, went beyond well-kept case notes, and 'pioneered novel methods of clinical research, including innovative principles of hospital management and record-keeping'.38 The connection is not made explicit, but Ryals moves on to discuss the state of the American Medical Profession during and after the American Civil War, drawing into prominence the fact that 'the 1830 s and 40 s saw the end of most attempts at state regulation and licensing of physicians',39 which left the field open to an unregulated and poorly trained medical profession. If one counter move to this was the formation of the American Medical Association in 1847, it seems evident that Mitchell and his colleagues' meticulous attention to detail - to close

36 Ernest Earnest, S. Weir Mitchell: Novelist and Physician, (Philadelphia: U of Pennsylvania P) 1950: 49.

37 As Earnest writes, 'For each [case] there was certain standardised data: name, place of birth, general health before the wound, place (geographic) wounded, description of wound, length of time before treatment, nature of treatment, extent of recovery, sensation, motion (if limb), comparative sizes of limbs if wound was in limb' (Earnest, 49).

38 Ryals, 52.

39 Ryals, 68-69. 
observation and accurate record keeping - was a different kind of reaction to this, one also born from what Stephanie Browner, writing of the 1850s, sees as the contest between 'earlier universalist therapeutics',40 that saw all illness as arising from the same cause, and its companion, taking shape in 'contemporary populist practitioners like Samuel Thomson who claimed that most patients and most illness could be treated by one regimen or a single tonic.'41 Mitchell's insistence on keeping meticulous note of individual circumstances and symptoms cuts against this universalist thrust. For Mitchell and his colleagues it was only through close observation of the individual case and its particularities, and the tracing of its path through accurate record keeping, that effective medical advance and cure could come.

Mitchell knew, however, as did his colleagues, that this 'very faithful clinical study' was beset with difficulty and error. Human error came into play as Morehouse delayed his writing up of the collected notes on epilepsy for so long that they were destroyed in a fire in his study, and could never - much to Mitchell's distress, and presumably annoyance, be published. More significant, however, than this human tardiness, was the nature of the conditions studied, and the pain encountered and endured by the soldiers in the wards. Notes could be taken, and yet pain remained elusive, tricky, deceptive; it is this trickery, intentional, on the part of the patient, or otherwise, that lead to the article on malingering.

Not only could pain be misleading, but the nature of medical practice - its necessary extension over time - could also lead to misunderstanding. Mitchell's awareness of the difficulties of recapitulating experience, particularly as it takes shape in the gap between the time of writing and the time of encounter with the patient in pain, and the possibility of forgetfulness and the inaccuracies of mental and spatial distance from the patient, really come to the fore in the later text,

40 Stephanie Patricia Browner, Profound Science and Elegant Literature: Imagining Doctors in Nineteenth-Century America (Philadelphia: U of Pennsylvania P) 2005: 31.

41 Browner, 31. 
Injuries of Nerves, which looks back and works through cases histories recorded during the Civil

War. In this retrospective account of his time at the Stump Hospital, he assuages his doubts over the veracity of his writing by claiming 'In delineating this form of pain '- and here he is writing of causalgia - the disease that is now particularly associated with Weir Mitchell - 'perhaps I cannot do better than transfer to these pages the account originally written whilst I was seeing almost daily numbers of persons suffering as I have described them.'42 It is a claim fraught with, if not contradictions, at least tensions. The 'delineation' of which he writes suggests a kind of clinical accuracy, but also provides only an outline, leaving a space within the medical terminology to be filled in by the patient's own experience, or, indeed, by artefacts stemming from the passage of time. This is not the only moment of hesitation in a claim that ends in confidence. Tentativeness suffuses the negative formulation of 'perhaps I cannot do better...' and results in a desire simply to 'transfer' experience from the earlier notebooks to the later textbook in a process that avoids the contamination of time, and perhaps undue reflection. Mitchell recognizes early on in the text that the interval between experience and the writing of that experience has its advantages, in making it possible 'to collect ...such details of later history as were needed to clear up or complete the story of symptoms or prognosis' 43 - at the moment of pain the story is incomplete, and perhaps the physician responds inadequately or simply cannot see something that will only appear in the fullness of time. And yet, after this moment of recognition that what one sees might not be the whole picture, comes the assertion of the doctor's authority. The closing phrase, insisting that the patients suffered 'as I described them', shifts the balance - and it is the doctor who holds the template, and the sufferer who fits himself to it. Description and experience here are identical though the reverberating doubts of the earlier part of the sentence cannot surely disappear into thin air. 
There are other difficulties, of course, in Mitchell's descriptions of physical suffering. The doubt is not just that things will change over time, but that the information gathered by the doctor is somehow questionable. Mitchell repeatedly falls back on such phrases as 'the pain which they described',44 allowing in that the possibility that the soldier in pain, even if he is not a malingerer, deliberately endeavouring to deceive, is not correct in his representation of what he feels. Mitchell goes further than suggesting a gap between the experience and the word used to catch it, in suggesting that the patient, suffering from causalgia, outlines 'a state of torture, which can hardly be credited' 45 and behaves 'with a care which seems absurd'.46 Both of these terms veer between acceptance of what is conveyed by the patient and a sense that the patient's behaviour has gone beyond the credible. As Mitchell goes on to write of one such patient in Injuries of Nerves, 'At last the patient grows hysterical, if we may use the only term which describes the facts'.47 It is an interesting phrase. There is a word that accurately describes what the doctor observes, and yet it is a word associated with women rather than with injured soldiers. Mitchell's hesitation over using the description 'hysteria' is one that is bound up in decorum and gender politics - the question is 'may he' use the word hysterical in relation to soldiers; is it permissible to do so? In writing of the same patient, a man called $\mathrm{H}$. in those notes, age 39, and designated Case 33, we are told that 'my notes describe him on entering our wards as presenting the following symptoms',48 and what follows is the quotation of Mitchell's own notes, made at the time: there is a deliberate choice to leave the language as it originally was; a choice not to edit or to remove ambivalence. The case notes read:

The hyperaesthesia of the palm was excessive, so that even to blow on it seemed to give pain. He kept it wrapped up and wet ... After a few weeks of this torment he became so sensitive that the rustle of a paper or of a woman's dress, the sound of feet, ... all appeared to increase his pain. His

\footnotetext{
44 'Injuries of Nerves', 196.

45 'Injuries of Nerves', 197.

46 'Injuries of Nerves', 197.

47 'Injuries of Nerves', 198.

48 'Injuries of Nerves', 201.
} 
countenance at this time was worn, pinched, anaemic, his temper irritable, and his manner so odd that some of the attendants believed him insane. When questioned as to his condition he assured me that every strong moral emotion made him worse, - anger or disappointment expressing themselves cruelly in the aching limb.49

It is a fascinating account, because the language of the piece is pulled in so many different directions. The passage is full of the phrases Mitchell came to rely on - 'it seemed' and 'it appeared' - and we hear the voice of the sceptical medical practitioner, made all the more present by the acceptance of this earlier version of events as it is re-read and published in 1872. But we also hear, I think, buried in Mitchell's account, the desperation of the soldier who felt the need to 'assure' Mitchell that strong emotion made things worse for his pain. The soldier goes beyond telling how things are; his words fail to find acceptance and he must push into persuasion. In these surroundings where the patient is not necessarily to be believed, and the attendants may have ways of understanding entirely at odds with the doctor and with the patient, the pain itself becomes an actor in this exchange. H's emotions must have a voice, and, as such, as Mitchell puts it, they 'express themselves - they find their own kind of language - cruelly in the aching limb'. That they express themselves 'cruelly' suggests a kind of personality to pain: they do not simply press out meaning, but do it with a kind of malice. Such delineations clearly link Mitchell's embodiments of pain back to such pictures as James Gillray's 1799 cartoon, 'The Gout', in which the inflamed foot of a man suffering from gout, is fiercely attacked by an evil-looking, sharp-taloned devil, intent on sinking claws and teeth into the tender foot.

This version of pain - one buzzing with the idea that pain can take on an embodied form, can have a mind and behaviour of its own that is somehow outside the remit of the body - at times infuses

49 'Injuries of Nerves', 201. 
Mitchell's medical writing. Writing of organs that perhaps only once in a life time feel pain, he asks if it is possible that there should be a system of nerves dedicated only to pain that may never, or only ever rarely, be called upon:

Are we to suppose that there exist always in these organs pain nerves, and that only once, perhaps, in a lifetime these filaments are to be aroused into activity? Or, as regards the skin, how shall we deal with the like difficulty if we choose to believe that everywhere are peculiar nerve fibres devoted only to transmitting painful sensations?50

Mitchell does not have the answer to this question of whether there are specific pain pathways, but his descriptions of the actions of the nerves carrying pain - their arousal and their devotion suggests something living; something outside the realms of the purely neurological. Alongside this, for the physician, it is a matter of choosing to believe if there are dedicated nerves for pain. It is as though two worlds are colliding: the world of observation, knowledge, and note-taking, and an older world view that relies on belief and a sense of the embodiment of pain in a malign shape. It is no mistake that when Mitchell gives his opinion on dedicated nerve pathways, he puts it in terms of his willingness to accept his conclusions: 'I am unwilling', he says, 'in view of the facts, to look upon pain as a distinct sense with afferent tracks peculiar to itself.'51

The doctor, uncertain of the functioning of the nervous system, recognises that his observations alone are insufficient: his judgment relies on his willingness to perceive things in a particular way; his willingness to translate the foreignness of the body into terms that he can understand. Pain, as Mitchell insists throughout his writing, speaks a foreign language. In trying to understand he writes of the possibility of a system of nerves devoted specifically to pain, and distinct from the system 
concerned with heat or touch: 'it is,' he writes, 'as if through a single tube were spoken various languages which could be only understood when, at its farther end, they reached the ear of the hearer native to each form of speech.'52 All kinds of impulses - sensation and pain - travel along the same nerves, like a message through a speaking tube, and it is only when they reach the end point that they are interpreted. The listener dedicated to warmth interprets the sensation in that way; whilst the listener listening out for pain will hear that as it comes thundering through the speaking tube. Mechanical disturbances along the path of the nerve are felt as pain, as the nerve translates the sensation into what Mitchell calls 'this sad language'. Pain, as Mitchell found from his experience with malingerers, could be - and, indeed, was - faked for the patient's advantage, and yet the difficulty lay in not allowing the knowledge of this possibility to preclude the possibility of its real existence. This analogy of speaking tube and nervous system gives a way of understanding Mitchell's own response to the pain of his patients, and their desire and difficulty in communicating it. It was the purpose of the doctor to place himself at the end of the speaking tube, and not just to hear, but to interpret, the language that came to his ear, in ways that others - even those in the same physical position - were unable to do without such training and experience.

It is this insistence on an interpretable voice that opens up some of the questions I have been addressing, particularly when seen in the context of the Stump Hospital. Mitchell wrote an article called 'Phantom Limbs' that appeared in Lippincott's Magazine of Popular Literature and Science in December 1871, and in it he writes about this subject that proved to be, as he rather pointedly puts it, 'of the strangest interest for even the least thoughtful observer'. As Mitchell points out, at least 500,000 men had lost an arm or a leg in the war, of whom many lived to tell the tale. What is interesting is Mitchell's account of these amputee's sense of their own suffering, for again the dispassionate doctor steps in and disregards the words in which their statements are made: 'it is' he

52 'Injuries of Nerves', 41. 
says, 'necessary to choose the cases for observation with great care, because the natural tendency of many witnesses, especially among the uneducated, is to color [sic] too strongly their answers in regard to parts which excite wonder or sympathy.' The sad language of pain that travels their nerves can be distorted and overemphasized when translated further into the spoken language of the sufferer.

The way that pain had no certain, recognizable outward manifestations - no demons with pliers are actually in evidence - made it possible for it to be used in this way by those seeking to avoid further fighting. Mitchell's views, in his 1885 textbook, Lectures on the Diseases of the Nervous System. Especially in Women, push further on this sense that the language pain speaks is perhaps deceptive. For him, hysteria is 'the fertile parent of evil' - it is the source of imagined bodily malfunction, and engenders pain without real, neurological cause. It is, as Mitchell puts it, 'a fruitful source of mimicry of disease, in its every form, from the mildest of dreamed up pains up to the most complete and carefully devised frauds. Its sensitiveness and mobility, its timidity and emotionalness, its greed of attention, of sympathy, and of power in all shapes, supply both motive and help, so that while we must be careful not to see mimicry in every hysteric system, we must, in people of this temperament, be more than usually watchful for this form of trouble, and at least reasonably suspicious of every peculiar or unusual phenomenon.

For Mitchell the natural instinct to imitate is, as he puts it, 'deeply human and exist in all of us in varying amounts.' For Mitchell each of us naturally has 'a tendency to automatic and unconscious imitation which is the parent of a good deal of mimicry in disease.' Surgeons, for example, find themselves imitating the facial grimaces of their patients. People cough when forced to listen to other people coughing. The husband of a pregnant woman finds himself vomiting in the morning. Imitation invades all areas of life. And this is the problem, for if the soldiers, feigning disease, in 
'On Malingering' were not just aware of this ability to imitate, but also used it to their own advantage, imitation could also take the individual unawares; could make him - or more probably her, in this instance - imitate something against her own will and knowledge. Mitchell suggests the necessity not just for vigilance, but for suspicion. All seemingly painful conditions could, in fact, be the artefacts of hysteria. Rather than speaking 'the sad language' of pain, hysterics speak the language of duplicity, though they may not themselves be aware of this. The voice of medical consensus, the well-judged and well-judging 'we' embodied in Mitchell's narrative voice, pronounces: 'we must be careful not to see mimicry in every hysteric symptom', and yet in saying this his suspicions are evident. Watchfulness becomes the dispassionate observation of the doctor, and circumvents the need to listen. The duplicitous voice of pain is conflated with the duplicitous voice of the patient, and it is seen as necessary, as good practice, to refuse to listen to either. The lessons learnt in the heat of battle about the deceptiveness of pain, are carried over into his work with hysterical women. Erin O'Connor overtly makes the connection between the soldier undone, unmanned, by the pain of amputation, and the hysterical woman, as both are rendered traditionally female by their suffering. O'Connor invokes the 'thrashing, twitching, and suffering from phantom pain stumps [which] showed a deep-rooted propensity for theatrical malingering that rivalled that of the hysteric', so that 'the dismembered man seemed to speak a fraudulent body language.'53

But Mitchell's own account goes further than this in recognizing the power of pain to un-man those who become involved with it. For him, the conventions of straight-talking, honest manliness are disrupted by pain and the ways in which it must be communicated, in a two-way unmanning undoubtedly recognized by Mitchell himself. If the strongest of men in pain can become a hysteric, unmanned to this female position by his suffering - as O'Connor recognizes - the malinger opts to 'whimper and sob in an unmanly manner'.54 Both produce the same response, but only one is

53 Erin O'Connor, Raw Material: Producing Pathology in Victorian Culture (Durham: Duke UP), 2000: 104. 54 On Malingering, 377? 
genuine. The doctor himself is not exempt from such gender fluidity, as he has only his instincts to work with, which give him nothing other than '“a woman's reason”'55 for his surmises.

Perhaps the upshot of this is the repeated self-referentiality of Mitchell's works. He gives his own case histories verbatim in his later works; he registers, at almost every opportunity, the potential to mislead of his patients' words - he uses the same formula drawing attention not just to the process of translation of sensation that the patient is undergoing, but his own profound scepticism in the face of the words that emerge from that translation. The reliance on his own version of events took extraordinary form in the fairly well-known text, the Case of George Dedlow, a supposedly autobiographical account of a man who had both arms and both legs amputated - it is an account that draws on Mitchell's neurological knowledge - it engages with the phenomenon of the phantom limb - but it also makes incredibly cheap jokes about the drunken staggering of limbs that have been stored for a couple of months in alcohol. What is interesting, in terms of some of the things I have been suggesting, is that this account was taken by many to be true, and as a result money and letters of support came flooding in to the Stump Hospital in Philadelphia as the readers of Lippincott's sought to help this unfortunate sufferer. The comedy of Mitchell's jeu d'esprit got lost

55 On Malingering, 371 ? 